\title{
Attitude and Learning Styles in Different Academic Achievement of Tertiary Students
}

\author{
Direk Teeraputon ${ }^{1}$, Pratya Nuankaew, ${ }^{2, *}$ \\ ${ }^{1}$ School of Education, University of Phayao, Phayao, 56000, Thailand \\ ${ }^{2}$ School of Information and Communication Technology, University of Phayao, Phayao, 56000, Thailand
}

Received August 25, 2020; Revised September 29, 2020; Accepted October 25, 2020

\begin{abstract}
Cite This Paper in the following Citation Styles
(a): [1] Direk Teeraputon, Pratya Nuankaew, "Attitude and Learning Styles in Different Academic Achievement of Tertiary Students," Universal Journal of Educational Research, Vol. 8, No. 11B, pp. 6178 - 6184, 2020. DOI: 10.13189/ujer.2020.082255.
\end{abstract}

(b): Direk Teeraputon, Pratya Nuankaew (2020). Attitude and Learning Styles in Different Academic Achievement of Tertiary Students. Universal Journal of Educational Research, 8(11B), 6178 - 6184. DOI: 10.13189/ujer.2020.082255.

Copyright $\bigcirc 2020$ by authors, all rights reserved. Authors agree that this article remains permanently open access under the terms of the Creative Commons Attribution License 4.0 International License

\begin{abstract}
The COVID-19 situation has transformed the teaching and learning process from the physical classroom to the virtual classroom. It can be said that this is a real technological disruption. This research aims to study attitudes and learning styles in different academic achievements of students in higher education. There are three research objectives: (1) to study attitudes and learning styles in different academic achievements, (2) to develop a questionnaire for analyzing the learning styles from attitudes towards students' learning styles, and (3) to assess the effectiveness of questionnaires, attitudes, and learning styles on different achievements. The data were collected from students at the University of Phayao who are at the undergraduate level in the academic year 2018-2020. It was obtained from 195 students from 17 schools and colleges. The research tools used in this research were questionnaires, frequency, percentage, mean, and standard deviation. The results of the study showed that students who responded to the questionnaires had different opinions on learning styles in different academic achievement. The factors affecting the learning style are at a high level.
\end{abstract}

Keywords Attitude towards Learning Styles, Educational Data Mining, Engineering Education, Learning Analytics, Learning Styles

\section{Introduction}

Learning in the $21^{\text {st }}$ century calls for a rapid change in the educational structure [1]-[4]. The characteristics of the changes in educational institutions emphasize the need for better learning centers. Collaboration between the lecturers, learners, and communities require a better coordination of operation. Changing the role of lecturers focuses on being educators who can promote or design courses to help enhance learning. Teaching approaches can be changed in the distance learning system based on their preferences through the internet. Also, it changes students who are learners to self-knowledge seekers. Lately, the physical environment, economy, society, culture, and technology have changed quickly. It makes current learners different from previous learners [3]-[6].

Current learners in this decade have a corresponding age-related to a modern youngster called "Generation Z" or "Gen Z" that have unique personality traits, thinking fast, making quick decision, have high confidence, and good technological skills [7]. However, they have low patience. Encouraging a learner in a teaching and learning environment in this age group is necessary to provide the correct and relevant guidance for a successful education program. One of the used methods is interest-based teaching or learning style that is unique for individuals [8], [9]. Recently, most learners who are receiving a high education have a different educational background. There are also differences in other areas including individuality, age, study preparation, and suitable learning styles. These varieties are important factors that researchers use to support learners with different learning styles that are for developing themselves and gain their achievements.

The study of attitudes and learning styles in different achievements are a part of a teaching and learning design 
[10] which allows lecturers to plan suitable teaching methods for learners. Learners can apply the correct learning (Learn how to learn) which is necessary. Besides, lecturers can analyze the learning style of each learner. They will be able to design an appropriate learning process for each learner effectively. Knowing the learning style of the learners will help in designing the teaching and learning methods to meet the needs of the learners. Therefore, the study of students' learning styles at the University of Phayao will encourage teachers to design instructions that take into the account of individuals' need to match with the nature of the students' learning as much as possible, and develop their learning efficiency to the best of their ability.

\subsection{Research Objectives}

There are three research objectives: (1) to study attitudes and learning styles in different academic achievements of students at the University of Phayao, (2) to develop a questionnaire for analyzing the learning styles from attitudes towards students' learning styles, and (3) to assess the effectiveness of questionnaires, attitudes, and learning styles on the different achievements of students at the University of Phayao.

\section{Materials and Methods}

There are three areas of literature reviews and related works: (1) Pattern, (2) Composition of the pattern, and (3) concept of learning styles.

\subsection{Pattern}

A pattern is either created or developed as a guideline for a particular way of work. Kemwimoottiwong [11] described the meaning of a pattern as a conceptual tool that a person uses to investigate words, answer knowledge, and understand the occurred phenomenon. They are created from ideas, experiences, metaphors or theories, and principles to express themselves in a certain way. Meanwhile, Bardo and Hartman [12] stated that the style in the social sciences is a collection of abstract statements about phenomena of interest to use in defining characteristics or values. Stoner and Wankel [13] described that the properties in the view of the model are a realistic simulation of a phenomenon to make it easier to understand the complex relationships of the phenomenon.

\subsection{Composition of Pattern}

Kemwimoottiwong [11] described four components of the pattern as follows: (1) Pattern leads to the consequence predictions that can be tested and observed. (2) The pattern indicates the relationships for explaining the problem of the mechanical phenomenon and current study subject. (3) The pattern encourages creating ideas, perceiving relationships, and pursuing knowledge. (4) The pattern has a higher structural relationship than a correlation relationship.

\subsection{Concept of Learning Styles}

Irvine [14] found that psychologists who studied learning styles were able to receive information via three cognitions: perception through vision (Visual), perception through hearing (Auditory), and perception through movement and sensation (Kinesthetic). It can be categorized into three major learning styles according to cognitive characteristics.

The visual learning styles (Visual): learners of this type need awareness and obtain information by looking at the teacher's gestures or other media to enhance understanding. This type of student usually sits in front of the class because they do not want anything to be obscured. They will learn well when looking at images or media demonstrations such as videos, slides, illustrated, etc. The characteristics type of this learner tends to take notes and collect information for various details to be considered.

Listening learning styles (Auditory): Learners of this type are good at learning by listening. They like lecture participation by speaking to exchange ideas with others. This type of student will learn the meaning and understand what is heard more than textual information or images. The equipment should be a type of tape recorder. It is the type of learning behavior that can be applied anywhere in the classroom. They want to hear what they are interested in regardless of the sitting position and types of event happening in front of the classroom. Also, they usually have some unique understandable symbols.

Movement and sensation learning style (Kinesthetic): Learners tend to be more skilled at doing it than watching, listening, examining, and being exposed. Moving the body or having to do it by themselves engages better learning. They often expose gestures when talking to other people. Moreover, they like touching and sitting near the door or any position where they can leave out easily. They often like to ask for permission from the instructor to leave the room. These types of learners do well on their own when they get the chance for exploring movement, picking-up an object, using the senses, moving the body, performing a play, and adapting with their experience.

The learning styles can be divided into three categories based on the perception channel: eye, ear, and body. When combining with the state of the person while perceiving information, there are three states: the state of consciousness, subconscious, and unconscious that are joined as the consideration. This idea can be the recommended learning styles that are suitable for learners. There are two pathways. It includes the component channels of information (Perceptual Pathways) and component conditions of the recognition information (States of Consciousness) which are linked to design six 
types of suitable learning for the learners.

The six models are the following.

Type 1: VAK is the type that learns best if they read and tell stories to others. It is considered a hard study learner, but they do not like sports.

Type 2: VKA is the type that learns best if they follow the assigned pattern, and ask questions continuously. They usually like to work in groups.

Type 3: AKV is the type that learns best if they teach others. They like to expand the time of telling stories but often have problems with reading and writing.

Type 4: AVK is the type that learns best if they can communicate with others. They speak reasonably and prefer the truth. They like to study history and on subjects that require all kinds of thinking when studying. They typically try to speak with others and make them understand. Nevertheless, they do not like studying sports.

Type 5: KVA is the type that learns best if they do thoughtful work in a quiet location. They can perform tasks that require physical exertion without telling the teacher. If they listen to the teacher a lot, they can get confused.

Type 6: KAV is the type that learns best if they can be physically active. They do not like staying still. They often have problems with reading and writing.

In the research methodology, there are four sections: Research Tools, Target Group, Research Procedures, and Statistical Methods.

\subsection{Research Tools}

Tools used in this research were questionnaires that inquire about the level of opinions on various factors and to distinguish the learning styles of individuals. The nature of the questionnaire is closed-ended for easy data collection. The questionnaires were distributed to the students. The details are presented in the following parts.

Part 1: Statement on explaining the purpose of data collection and how to use the information beneficently.

Part 2: General information questionnaire of the respondents consisted of affiliation, faculties, year, gender, and average grade level. It is a list of surveys (Check List) and writing responses.

Part 3: Questionnaire about self-assessments to study attitudes affecting different learning styles for each individual, which has the criteria for determining the weight of 5 levels of evaluation, according to the Likert Scale method as follows: strongly disagree, disagree, neither agree nor disagree, agree, and strongly agree.

\subsection{Target Group}

The data were collected from students enrolled in an undergraduate degree program in the academic year of 2018-2020 at the University of Phayao. Sample size determination was applied with accidental sampling as a sample group selection to obtain the required number of 195 samples from 17 schools and colleges at the University of Phayao.

\subsection{Research Procedures}

Primary Data: The researcher studied and collected the data of 195 questionnaires. It was a tool to collect the data of the population sample, including 195 students at the University of Phayao. Secondary Data: The researcher made a study on the books, academic articles, research, related works, and thesis from databases of undergraduate and graduate students of various universities via the Internet.

\subsection{Statistical Methods}

The statistical methods were in two processes: (1) analyzing general information of respondents by calculating the frequency and percentage, (2) evaluating criteria by using the principle of a class interval. It was divided into five classes from the average score obtained from the questionnaire.

The calculation done showed that the highest score is 5 and the lowest score is 1 . These scores were then applied to compute a mid-range by using the class interval formula as follows:

$$
\begin{aligned}
\text { class interval }= & (\text { highest score }- \text { lowest score }) /(\text { number } \\
& \text { of classes }) \\
= & (5-1) / 5 \\
= & 0.8
\end{aligned}
$$

Therefore, the interval of each class is 0.8 , which can set the criteria for the mean scoring of self-assessment level to study attitudes affecting the learning styles of students at the University of Phayao; results are shown in Table 1.

Table 1. Mean score and Interpretation

\begin{tabular}{|c|c|}
\hline Mean score & Interpretation \\
\hline $4.21-5.00$ & Highest accepted level \\
\hline $3.41-4.20$ & High accepted level \\
\hline $2.61-3.40$ & Medium accepted level \\
\hline $1.81-2.60$ & Low accepted level \\
\hline $1.00-1.80$ & Lowest accepted level \\
\hline
\end{tabular}

After doing the calculation, the level of factors that affected the learning styles of different individuals was analyzed. The level is calculated by mean to describe the mean of the data obtained from part two of the questionnaire to study attitudes towards different learning styles of different individuals. Standard Deviation was used to describe the variance of the data obtained from part two of the questionnaire in order to study attitudes towards different learning styles for each individual.

\section{Experimental Results}

This research aims to study attitudes towards different 
learning styles of individuals. The researcher collected 195 questionnaires from the sample group of 195 students from 17 schools and colleges at the University of Phayao. The analysis results were divided into two parts: (1) summary of data collected, (2) attitude toward the factors and learning styles.

\subsection{Summary of Data Collected}

The summary of the collected data was divided into two perspectives including (1) gender and academic year, and (2) schools and colleges, which is shown in Table 1 and Table 2.

According to Table 2, the study results show that most of the respondents were females with a number of 125 samples $(64.10 \%)$, and males with a number of 70 samples $(35.90 \%)$, respectively. Furthermore, most of the students who responded to the questionnaire were third-year students with the total number of 91 samples (46.67\%), followed by second-year students with a total number of 51 samples $(26.16 \%)$, fourth-year students with a total number of 24 samples (12.31\%), first-year students with a total number of 23 samples (11.79\%), and fifth-year students with a total number of 7 samples (3.59\%), respectively.

The results of the study according to Table 3 showed that the number of students who answered the questionnaire classified by the school includes 35 samples from the School of Medicine, accounting for 17.95 percent; 29 samples from the School of Management and Information Science, accounting for 14.87 percent; 28 samples from the School of Education, accounting for 14.36 percent; 19 samples from the School of Information and Communication Technology, accounting for 9.74 percent.

Moreover, the students from the School of Engineering, School of Medical Sciences, and the School of Law have the same number of 12 samples, accounting for 6.15 percent. There were 10 samples from the School of Liberal Arts, accounting for 5.13 percent; 7 samples from the School of Pharmaceutical Sciences, accounting for 3.59 percent. The students from the School of Allied Health Sciences, and the School of Architecture and Fine Arts have the same number of 6 samples, accounting for 3.08 percent. Additionally, there were 5 samples from the School of Political and Social Science, accounting for 2.56 percent; 3 samples from the School of Science, accounting for 1.54 percent. There were only 2 samples from the School of Energy, and the Environment and School of Nursing, accounting for 1.03 percent, and 1 sample from the School of Dentistry, accounting for 0.51 percent, respectively.

Table 2. Data collection classified by gender and academic year

\begin{tabular}{|c|c|c|c|c|c|c|}
\hline Gender & Number & Year 1 & Year 2 & Year 3 & Year 4 & Year 5 \\
\hline \multirow{2}{*}{ Male } & 70 & 6 & 20 & 34 & 8 & 1 \\
& $(35.90 \%)$ & $(3.07 \%)$ & $(10.26 \%)$ & $(17.42 \%)$ & $(4.10 \%)$ & $(0.51 \%)$ \\
\hline \multirow{2}{*}{ Female } & 125 & 17 & 29 & 58 & 16 & 6 \\
& $(64.10 \%)$ & $(8.72 \%)$ & $(14.87 \%)$ & $(29.74 \%)$ & $(8.21 \%)$ & $(3.08 \%)$ \\
\hline \multirow{2}{*}{ Total } & 195 & 23 & 51 & 91 & 24 & 7 \\
& $(100 \%)$ & $(11.79)$ & $(26.15)$ & $(46.67 \%)$ & $(12.31 \%)$ & $(3.59 \%)$ \\
\hline
\end{tabular}

Table 3. Data collection classified by school

\begin{tabular}{|l|c|c|}
\hline \multicolumn{1}{|c|}{ Schools and Colleges } & Respondents & Percentage \\
\hline School of Agriculture and Natural Resources & 6 & 3.08 \\
\hline School of Information and Communication Technology & 19 & 9.74 \\
\hline School of Science & 3 & 1.54 \\
\hline School of Engineering & 12 & 6.15 \\
\hline School of Education & 28 & 14.36 \\
\hline School of Energy and Environment & 2 & 1.03 \\
\hline School of Nursing & 2 & 1.03 \\
\hline School of Medicine & 35 & 17.95 \\
\hline School of Pharmaceutical Sciences & 7 & 3.59 \\
\hline School of Medical Sciences & 12 & 6.15 \\
\hline School of Allied Health Sciences & 6 & 3.0 \\
\hline School of Dentistry & 1 & 0.51 \\
\hline School of Law & 12 & 6.15 \\
\hline School of Management and Information Science & 29 & 14.87 \\
\hline School of Liberal Arts & 10 & 5.13 \\
\hline School of Architecture and Fine Arts Total & 6 & 3.08 \\
\hline School of Political and Social Science & 5 & 2.56 \\
\hline
\end{tabular}




\subsection{Attitude toward the Factors and Learning Styles}

This section presents attitudes towards learning factors and pattern of learning styles, which were divided into two parts: (1) attitude toward perception of learning styles, and (2) attitude toward pattern of learning styles, as shown in Table 4 and Table 5.

Table 4. Attitude toward perception of learning styles

\begin{tabular}{|c|c|c|c|}
\hline Questions & $\bar{X}$ & S.D. & Interpretation \\
\hline $\begin{array}{l}\text { - Students study well by } \\
\text { reading from the slides of } \\
\text { the lecturer's teaching }\end{array}$ & 3.73 & 0.87 & High Accepted \\
\hline $\begin{array}{l}\text { - Students can do it well } \\
\text { when students try learning } \\
\text { by doing it themselves }\end{array}$ & 3.98 & 0.82 & High Accepted \\
\hline $\begin{array}{l}\text { - Students can remember } \\
\text { what they hear in class } \\
\text { better than what they have } \\
\text { read }\end{array}$ & 3.78 & 0.82 & High Accepted \\
\hline \begin{tabular}{llr} 
- & \multicolumn{2}{l}{ Students can understand } \\
the lessons & better when \\
students & read & by \\
themselves & & \\
\end{tabular} & 3.80 & 0.91 & High Accepted \\
\hline $\begin{array}{ll}- & \text { Students study well when } \\
\text { teachers provide lectures }\end{array}$ & 3.74 & 0.87 & High Accepted \\
\hline $\begin{array}{l}\text { - Students understand what } \\
\text { they learn well when they } \\
\text { have to play role-playing }\end{array}$ & 3.67 & 0.93 & High Accepted \\
\hline $\begin{array}{l}\text { - Students learn better by } \\
\text { listening to others } \\
\text { speaking in the class }\end{array}$ & 3.67 & 0.88 & High Accepted \\
\hline $\begin{array}{llll}\text { - } & \text { Students study well from } \\
\text { reading rather than } \\
\text { listening }\end{array}$ & 3.69 & 0.97 & High Accepted \\
\hline $\begin{array}{ll} & \text { Students study well when } \\
\text { participating in activities }\end{array}$ & 3.82 & 0.83 & High Accepted \\
\hline Mean & 3.76 & 0.88 & $\begin{array}{c}\text { High } \\
\text { Accepted }\end{array}$ \\
\hline
\end{tabular}

From Table 4, it was found that the students who answered the questionnaire had attitudes towards different levels of satisfaction towards the factors of learning styles at the University of Phayao.

The factor influencing the learning style is at a high level $\left(x^{-}=3.76\right)$, by considering each factor. The factor that obtained the highest score is the students who can do it well when students try learning by doing it themselves $\left(\mathrm{x}^{-}=\right.$ 3.98), followed by the students study well when participating in activities $\left(\mathrm{x}^{-}=3.82\right)$; the students can understand the lessons better when students read by themselves $\left(\mathrm{x}^{-}=3.80\right)$; the students can remember what they hear in class better than what they have read $\left(\mathrm{x}^{-}=\right.$ $3.78)$; the students study well when teachers provide lectures $\left(\mathrm{x}^{-}=3.74\right)$; the students study well by reading from the slides of the lecturer's teaching ( $\left.\mathrm{x}^{-}=3.73\right)$; the students study well from reading rather than listening $\left(\mathrm{x}^{-}=3.69\right)$; and the factors with the lowest mean are the students understand what they learn well when they have to play role-playing and the students learn better by listening to others speaking in the class $\left(\mathrm{x}^{-}=3.67\right)$.
Table 5. Attitude toward pattern of learning styles

\begin{tabular}{|c|c|c|}
\hline Learning Style & Number & Percentage \\
\hline V-A-K & 30 & 15.38 \\
\hline V-K-A & 37 & 18.97 \\
\hline A-K-V & 35 & 17.95 \\
\hline A-V-K & 24 & 12.31 \\
\hline K-V-A & 35 & 17.95 \\
\hline K-A-V & 34 & 17.44 \\
\hline Total & 195 & 100 \\
\hline
\end{tabular}

From Table 5, it was found that the students who answered the questionnaire had attitudes towards the different levels of satisfaction towards the patterns of learning styles at the University of Phayao.

The learning style is mainly the $\mathrm{V}-\mathrm{K}-\mathrm{A}$ with a number of 37 samples (18.97\%), followed by the A-K-V and K-V-A learning styles with a number of 35 samples (17.95\%), the $\mathrm{K}-\mathrm{A}-\mathrm{V}$ learning style with a number of 34 samples (17.44\%), the V-A-K learning style with a number of 30 samples $(15.38 \%)$, and the A-V-K learning style with a number of 24 samples (12.31\%), respectively.

\section{Conclusion and Discussion}

From the data collections, it was found that most of the students were female learning in the third academic year; in accordance with the information of the education service system and division of educational service at the University of Phayao regarding the number of undergraduate students in the academic year of 2018-2020.

The sample group comprised of 5,941 males and 12,222 female students. Additionally, there were 4,402 students in the first year, 3,835 students in the second year, 4,457 students in the third year, and 4,252 in the fourth year of the academic semester (Educational Service Division, 2019). It can be seen that the number of the female population is larger than the male. Moreover, the number of population in the third year is more than in other classes. In the sample selection with the use of accidental sampling, most of the samples were females in the third academic year.

The results of the study presented the opinion level on the factors towards the opinion level influencing the learning styles in the different achievements of students at the University of Phayao.

It was found that students tried learning by doing it themselves when they can do it well. It is the grading factor of students by giving opinions at the highest level $\left(\mathrm{x}^{-}=\right.$ 3.98). It was found that when learning management is applied to the process of learning by doing it can improve the learning skills of students studying in higher education. They were at a high-quality level, which was at a high percent of the total number of students. It was indicated by the assessments, experimental conducts, empirical results, and students' work evaluations. 
Moreover, this study found that the V-K-A learning style is the type of person who learns when he/she follows a pattern and attends to the questions on a continuous basis. They like working as a team especially ( 37 samples). There is a figure of 18.97 percent with the highest number in accordance with the concept of learning [15]. The Visual learner (V) with a conscious state, Kinesthetic learner (K) with a subconscious state, and Auditory learner (A) with an unconscious state will be considered as the V-K-A learning style.

Counseling psychologists stated that most of us have a unique learning style, and these learning styles are fixed at about the age of being 7 years old. However, the learning styles may change for some children, which in this case occasionally happens. Particularly recognizing the learning styles of the students can be useful in the instructional design for teachers. It can also encourage teachers to help students who have learning problems by guiding their thinking and learning styles as much possible under their discretion. Although the students have a unique learning style, none of the learners used only one form of learning all the time. Multiple overlaps in learning with the most dominant forms will be used more than others by the students.

\section{Suggestion}

According to the results, it was found that the teaching and learning style should be provided for students with regards to their visual learning style, auditory learning style, and kinesthetic learning style. It will enhance the learners to achieve the best in learning. Therefore, the instructor should apply the results of this study to enhance the teaching of the relevant subjects with a teaching design that is orientated around teaching activities that are relevant toward the course subjects. The organization of teaching and learning activities should belong to a group of learners, basic skills, and attitudes of learners. As a result, learners can access and apply their knowledge much more effectively. Also, other learning styles should be studied to find the differences in teaching styles that are suitable for learners.

\section{Acknowledgements}

This research is part of the research on "The Study of Trends and Impacts of Disruptive Technology on the Education System at the School of Information and Communication Technology, the University of Phayao".

This research is supported by two organizations: The School of Education, University of Phayao and The School of Information and Communication Technology, University of Phayao. The authors would like to thank the advisor, lecturers, students, technicians, and all respondents for their entire support.

\section{REFERENCES}

[1] C. Medel-Anonuevo, T. Ohsako, and W. Mauch, "Revisiting Lifelong Learning for the 21st Century," 2001, Accessed: Aug. 25, 2020. [Online]. Available: https://eric.ed.gov/?id= ED469790.

[2] J. Collins, "Lifelong Learning in the 21st Century and Beyond," RadioGraphics, vol. 29, no. 2, pp. 613-622, Mar. 2009, doi: 10.1148/rg.292085179.

[3] W. Nuankaew, K. Phanniphong, S. Bussaman, D. Teeraputon, and P. Nuankaew, "Mentoring Model in an Active Learning Culture for Undergraduate Projects," Adv. Sci. Technol. Eng. Syst. J., vol. 5, no. 4, pp. 805-815, 2020, doi: 10.25046/aj050495.

[4] P. Nuankaew, "Clustering of Mindset towards Self-Regulated Learning of Undergraduate Students at the University of Phayao," Adv. Sci. Technol. Eng. Syst., vol. 5, no. 4, pp. 676-685, 2020, doi: 10.25046/aj050481.

[5] P. Nuankaew and P. Temdee, "Matching of compatible different attributes for compatibility of members and groups," Int. J. Mob. Learn. Organ., vol. 13, no. 1, pp. 4-29, 2019.

[6] P. Nuankaew, W. Nuankaew, S. Bussaman, and P. Jedeejit, "Education mining in the relationship between general knowledge and deep knowledge for lifelong learning," in 2017 14th International Conference on Electrical Engineering/Electronics, Computer, Telecommunications and Information Technology (ECTI-CON), Jun. 2017, pp. 694-697, doi: 10.1109/ECTICon.2017.8096333.

[7] C. Giunta, "An emerging awareness of generation $Z$ students for higher education professors," Arch. Bus. Res., vol. 5, no. 4, 2017.

[8] M. Asgari, S. Ketabi, and Z. Amirian, "Interest-Based Language Teaching: Enhancing students' interest and achievement in L2 reading," Iran. J. Lang. Teach. Res., vol. 7, no. 1, pp. 61-75, 2019.

[9] P. Nuankaew, W. Nuankaew, K. Phanniphong, S. Imwut, and S. Bussaman, "Students Model in Different Learning Styles of Academic Achievement at the University of Phayao, Thailand," Int. J. Emerg. Technol. Learn. IJET, vol. 14, no. 12, pp. 133-157, Jun. 2019.

[10] A. Bandura, "Self-efficacy: toward a unifying theory of behavioral change.," Psychol. Rev., vol. 84, no. 2, p. 191, 1977.

[11] C. Kemwimoottiwong, "Innovation of Knowledge-based Hyper-multimedia to Promote a Culture of Using ICT Creatively for Adolescents," Comput. Technol. Appl., vol. 4, no. 5, 2013.

[12] J. W. Bardo and J. J. Hartman, "Urban Sociology: A systematic approach,” Itasa IL FE Peacock Publ., 1982.

[13] J. A. Stoner and C. Wankel, "Management, 3'd ed," Ed. Englewood Cliffs, 1986.

[14] J. J. Irvine and D. E. York, "Learning Styles and Culturally 
Diverse Students: A Literature Review.," 1995.

[15] A. Satiman, S. Boonlue, and T. Sittiwong, "Effects of using problem-based learning activities via internet on self-directed learning and achievement of higher education students," ICT J. Learn. Dev., vol. 1, no. 3, 2009. 